\title{
Influences of season, cycle and breed on follicular growth rates in sheep
}

\author{
L. P. Cahill and P. Mauléon \\ I.N.R.A.-Station de Physiologie de la Reproduction, 37380 Nouzilly, France
}

\begin{abstract}
Summary. Follicular growth was studied in 16 ewes of different breeds (Romanov, mean ovulation rate $3 \cdot 0$, and Ile-de-France, mean ovulation rate 1.6 ), stage of cycle (Day 0 or 7) and season (December and June).

The follicular growth rates, determined by measuring the mitotic index before and $2 \mathrm{~h}$ after colchicine treatment, varied greatly between animals studied and did not vary significantly between breeds, time of cycle or season. From 3 layers of granulosa cells until antrum formation the mitotic index increased slowly but then the follicles grew rapidly reaching maximum growth rate at a follicular diameter of $0.85 \mathrm{~mm}$; thereafter the mitotic index decreased almost to zero in preovulatory follicles. The mean time for a follicle to pass from 3 layers of granulosa cells (200 cells) to preovulatory size $\left(3 \times 10^{6}\right.$ cells) was estimated to be about 6 months.

The total number of normal follicles with $>3$ layers of granulosa cells in Ile-deFrance ewes was similar in the anoestrous ( 3 ovaries studied) and breeding ( 3 ovaries) seasons, but there were more antral follicles in the latter.

Highly significant correlations existed in each ewe between the number of follicles and the mean mitotic index per class, suggesting the existence of an intraovarian mechanism regulating folliculogenesis.
\end{abstract}

\section{Introduction}

A recent study of the total follicular populations in ewes of high and low ovulation rate has shown that there are more follicles at each stage throughout the entire growth phase in ewes with a higher ovulation rate (Cahill, Mariana \& Mauléon, 1979). However, the number of follicles that are at a particular stage at a given point in time, e.g. those at a stage at which ovulation can be induced, is not only dependent on the number of follicles throughout the growth phase but also the speed with which these follicles pass through this phase.

The purpose of this paper is to study the second factor, i.e. the speed at which follicles grow throughout the growth phase, and some factors influencing this characteristic in sheep.

The method used to determine follicular growth rate was to study the mitotic index, i.e. the proportion of cells observed in mitotic division, and this index was correlated to a time basis according to the function described by Puck \& Steffen (1963). These authors developed their analysis of cell division from mammalian cells cultured in vitro and initially in this study we have verified this same function in vivo. The duration of mitosis was determined for this analysis by determining the mitotic index at $2 \mathrm{~h}$ after colchicine treatment which blocks all cell division at the metaphase-anaphase stage. 


\section{Materials and Methods}

A group of 6 Romanov (mean ovulation rate 3.0) and 6 Ile-de-France (mean ovulation rate 1.6) ewes were ovariectomized during December (mid-breeding season) on Day 0 (3 ewes of each breed) and Day 7 ( 3 ewes of each breed) and 2 ewes of each breed were ovariectomized during June (mid-anoestrous season). An additional ewe was also ovariectomized in June to verify in vivo the accumulation function of granulosa cells at the metaphase-anaphase stage after colchicine injection. At the start of the experiment all ewes were 30 months of age, parous, cyclic, housed together and had not been treated recently with PMSG.

At ovariectomy, under fluothane anaesthesia, the left ovary was removed and $50 \mathrm{mg}$ colchicine were injected into the jugular vein. After $2 \mathrm{~h}$ the right ovary was removed. The additional ewe also received $50 \mathrm{mg}$ colchicine but the left and right ovaries were removed 2 and $6 \mathrm{~h}$ later respectively. All ovaries were fixed in Bouin-Hallande's solution, sectioned at a thickness of $7 \mu \mathrm{m}$, mounted, stained with Feulgen's stain and inspected microscopically.

\section{Measurements of follicles}

The nucleolus in the nucleus of the oocyte was used as the marker for each follicle. On the section where the nucleolus was found the area of the follicle was measured by the methods previously described (Cahill et al., 1979). Only follicles with 3 or more layers of granulosa cells and with less than 4 pyknotic bodies in the section where the nucleolus was found were considered. The follicular population was considered in two parts.

(1) For follicles $<0.20 \mathrm{~mm}$ in diameter, i.e. before antrum formation, the section containing the nucleolus and each adjoining section were inspected and the number of mitotic figures was noted. The number of granulosa cells was counted in one section of one follicle per class (see below) in all ovaries, and an overall regression of follicle size and number of cells was calculated. Since any mitotic figures seen were only counted in one section, although often present in two sections, a correction factor was used to adjust the number of cells counted (Abercrombie, 1946). The classes chosen were for follicles of $<0.06,0.06-0.10$ and $0.11-$ $0.20 \mathrm{~mm}$ in diameter and 15 follicles or as many as were present for each class were considered.

(2) For those follicles $>0.20 \mathrm{~mm}$ in diameter, a graticule situated in the ocular lens of the microscope and of known area was focused randomly on the granulosa cells and the number of mitotic figures was recorded. For each follicle this procedure was repeated 20 times. To determine the number of granulosa cells per unit area of the graticule, the number of cells was counted 20 times for one follicle per class per ovary, and a mean number of cells per unit area per class was calculated. The overall mean number of cells per unit area was $48 \cdot 5$. For the follicle sizes $0.21-0.35$ and $0.36-0.62 \mathrm{~mm}$ in diameter, 10 follicles in each class, and all follicles in classes $0.63-1.13,1 \cdot 14-2.00,2.01-4.00$ and $\$ 4.01 \mathrm{~mm}$ in diameter were considered.

The mitotic index was calculated from the number of mitotic figures per total number of granulosa cells. Follicles from ovaries collected immediately before colchicine treatment were considered as 'active' if at least one mitotic figure was seen in the sections examined.

\section{Determination of follicular characteristics}

The areas of the oocyte and antrum, in addition to the area of the follicle, were measured in a sample of follicles ( 6 per ovary) on the section where the nucleolus was located, by using the methods previously described (Cahill et al., 1979).

Oocyte diameter was calculated from the area of the oocyte assuming it to be circular. The proportion of the follicle occupied by the antrum was calculated from the measured areas of the follicle and antrum. The number of granulosa cells per follicle was calculated for the 
preantral follicles from the regression of the number of cells against follicle size, taking into account the thickness of the section, assuming the follicle to be spherical and using a correction factor (Abercrombie, 1946). For the antral follicles, the volume of granulosa tissue was calculated from the volume of the follicle (assuming the follicle to be spherical) less the proportion of the follicle occupied by the antrum and the volume of the oocyte. The number of granulosa cells per unit volume was calculated from the mean number of cells, calculated as above, and the thickness of the section, and the number of cells was adjusted by using a correction factor (Abercrombie, 1946).

\section{Follicular populations}

The follicular population was determined in 3 of the ovaries from the 2 Ile-de-France ewes ovariectomized in June (anoestrus) and in 3 ovaries from 2 Ile-de-France ewes ovariectomized on Day 7 during the breeding season (December). The total number of follicles with more than 3 layers of granulosa cells was counted in the manner previously described (Cahill et al., 1979).

\section{Statistical analysis and calculations}

Analyses of the mitotic indices (M.I.), number of granulosa cells per follicle $<0.20 \mathrm{~mm}$ in diameter and the number of cells per unit area for larger follicles were carried out using split-plot analysis of variance. Using the formula described by Puck \& Steffen (1963), the duration of mitosis $(t)$ can be calculated as $2 \times \log (1+$ M.I. before colchicine $) / \log (1+$ M.I. $2 \mathrm{~h}$ after colchicine). The time (DT) for the number of granulosa cells to double for each class was calculated from the formula: $0.301 \times t / \log (1+$ M.I. before colchicine) where $t$ is the duration of mitosis. The time $(h)$ to pass through each class was calculated from the formula DT $\left(\log N-\log N_{0}\right) / 0.301$ where $N_{0}$ and $N$ are the numbers of cells at the beginning and end of a given class respectively.

\section{Results}

\section{Follicular characteristics}

Oocyte diameter. No significant differences were found between cycle, breed or season in the size of the oocyte in relation to follicular size. After pooling the data, the oocyte diameter increased between follicular diameters of 0.06 and $0.30 \mathrm{~mm}$ and then remained relatively stable as follicular size increased (Text-fig. 1a).

Size of antrum. There was no significant difference between breeds, cycle or season in the relationship between the proportion of the follicle occupied by the antrum and follicular size during the antrum development stage and the data have been pooled (Text-fig. 1b). Extrapolation of these regression lines showed that antrum formation began at similar follicular diameters of 0.216 and $0.220 \mathrm{~mm}$ for the Romanov and Ile-de-France ewes respectively. At a follicular diameter of about $0.85 \mathrm{~mm}$ the relative size of the antrum increased more slowly and finally occupied $93 \%$ of the volume of the preovulatory follicle.

Number of granulosa cells per follicle. The increase in the number of granulosa cells per increase in follicular size was clearly exponential as shown by the logarithmic relationship (Text-fig. 1c). At a follicular diameter of $0.06 \mathrm{~mm}$ when there were approximately 3 layers of granulosa cells there were about 200 cells, at the start of antrum formation there were 5000 cells, and at the preovulatory stage 3300000 granulosa cells. The number of granulosa cells per follicle size did not vary significantly between breeds, cycle or season. 


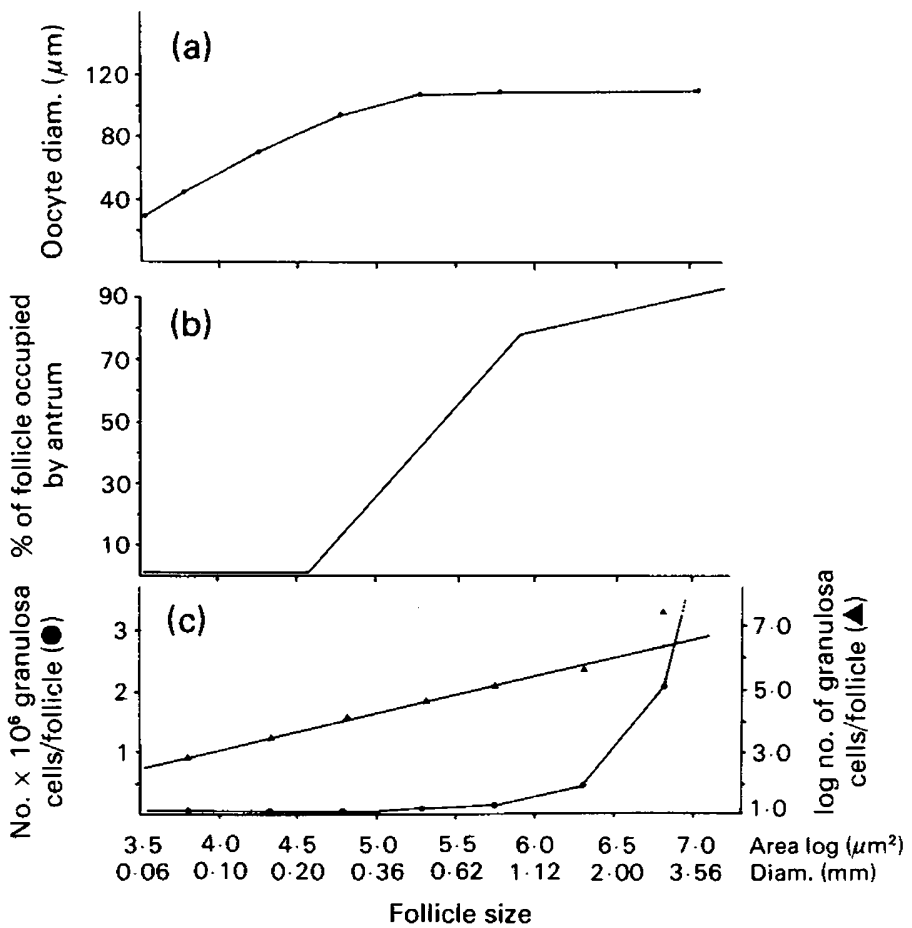

Text-fig. 1. Mean follicular characteristics in relation to follicular size in ovaries from 8 Romanov and 8 Ile-de-France ewes.

\section{Determination of the accumulation of mitotic figures after colchicine treatment}

All follicles were pooled into 2 large classes of approximately equal numbers of follicles. As follicular size increased the mitotic indices increased; at 2 and $6 \mathrm{~h}$ after colchicine treatment the $\log (1+$ M.I. $)$ was $0.001 \pm 0.001(n=28)$ and $0.003 \pm 0.002(n=30)$ for follicles $<0.10 \mathrm{~mm}$ in diameter and $0.004 \pm 0.001(n=31)$ and $0.011 \pm 0.002(n=33)$ for follicles $>0.11 \mathrm{~mm}$. Considering the variation in the mean mitotic indices at each time it was considered that extrapolation of these lines would pass through the origin.

\section{Influence of cycle on follicular growth rates}

There were no significant differences within breeds between Day 0 or Day 7 in the mitotic index per follicular size either before or $2 \mathrm{~h}$ after colchicine treatment.

\section{Influence of breed on follicular growth rates}

To compare breed differences results from Days 0 and 7 were pooled. There was a large variation between animals and no significant difference between breeds in the mitotic index per follicular class at either time (Text-fig. 2). There was relatively little increase in the mitotic index for follicles $<0.28 \mathrm{~mm}$ in diameter but the mitotic index increased rapidly to a maximum at $0.85 \mathrm{~mm}$ diameter and then decreased to almost zero in the preovulatory follicles. When the proportion of active follicles was considered, i.e. those follicles in which at least one mitotic figure was seen, there were again no significant differences between breeds (Table 1). 


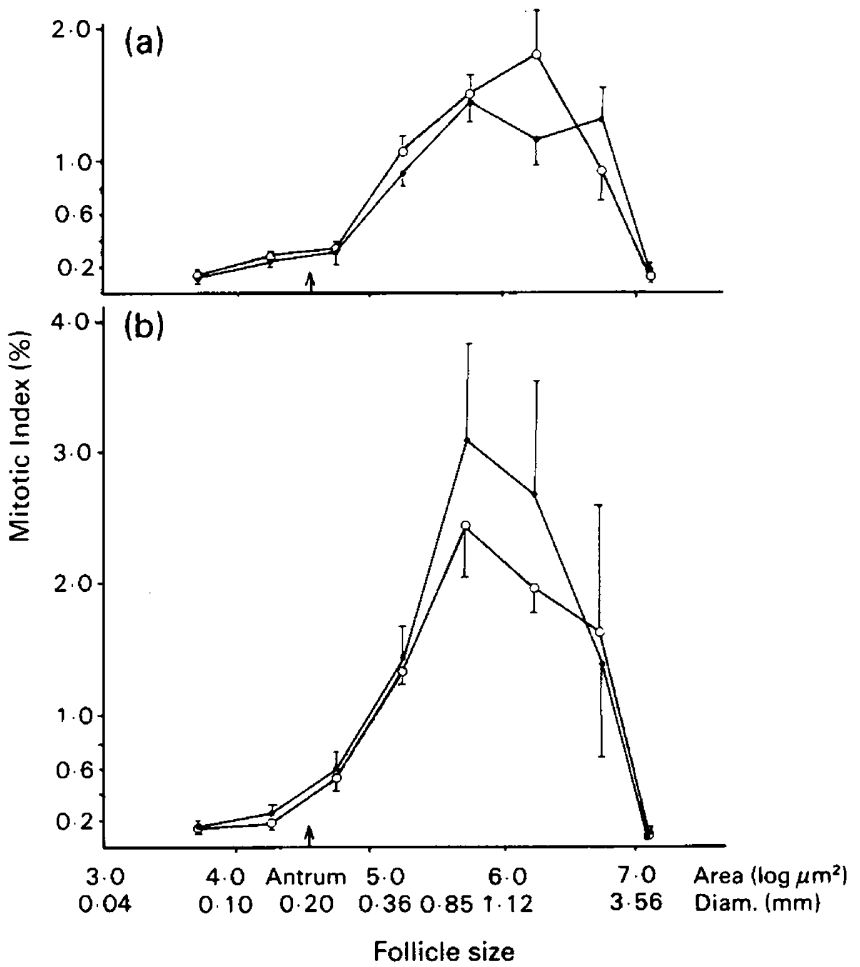

Text-fig. 2. The mean mitotic indices (a) before and (b) $2 \mathrm{~h}$ after colchicine treatment for various follicle classes in ovaries from 6 Romanov $(O)$ and 6 Ile-de-France $(O)$ ewes.

\section{Influence of season}

Follicular growth rates. There were no significant differences in the mitotic index per follicular size of sheep studied in December and June. Nor was there any significant difference in the proportion of active follicles (Table 1).

Follicular populations. Although there was no significant difference in the total number of non-atretic follicles per ovary (anoestrus, $108.3 \pm 2.4$; oestrus, $119.7 \pm 8.0$ ), there were significantly more follicles $(P<0.05)$ with an antrum in the ovaries removed during December $(44.0 \pm 3.8)$ than in June $(30.3 \pm 3.0)$. There were also more atretic follicles during December $(8.6 \pm 0.9)$ than in June $(3.5 \pm 2.5)$ but this difference was not significant. The total number of preantral follicles was similar in December and June, $75.7 \pm 8.7$ and $78.0 \pm 4.5$ respectively, but there were slightly more small preantral follicles, i.e. $<0.10 \mathrm{~mm}$ diameter, in June $(42.6 \pm$ $4 \cdot 1)$ than in December $(34 \cdot 3 \pm 4 \cdot 9)$.

Table 1. The mean ( \pm s.e.m.) percentages of active follicles per class in ovaries of ewes during December (breeding season) and June (anoestrus)

\begin{tabular}{|c|c|c|c|c|c|c|c|}
\hline \multirow{2}{*}{\multicolumn{2}{|c|}{ No. of ovaries }} & \multicolumn{6}{|c|}{ Follicle classes by diameter $(\mathrm{mm})$} \\
\hline & & $<0.06$ & $0.06-0 \cdot 10$ & $0.11-0.20$ & $0.21-0.35$ & $0.36-0.62$ & $\geqslant 0.63$ \\
\hline \multicolumn{8}{|l|}{ Breeding season } \\
\hline Romanov & 6 & $1 \cdot 2 \pm 2 \cdot 0$ & $20 \pm 3 \cdot 0$ & $47 \pm 7 \cdot 7$ & $94 \pm 6 \cdot 7$ & 100 & $98 \pm 3 \cdot 3$ \\
\hline Ile-de-France & 6 & $2 \cdot 6 \pm 2 \cdot 2$ & $19 \pm 3 \cdot 1$ & $52 \pm 5 \cdot 8$ & $89 \pm 4 \cdot 8$ & 100 & $97 \pm 8 \cdot 3$ \\
\hline \multicolumn{8}{|l|}{ Anoestrous season } \\
\hline $\begin{array}{l}\text { Romanov + } \\
\text { Ile-de-France }\end{array}$ & 4 & $6 \pm 1 \cdot 5$ & $20 \pm 7 \cdot 0$ & $60 \pm 5.9$ & 100 & 100 & 100 \\
\hline
\end{tabular}




\section{Correlation between mitotic index and number of follicles per class}

In each of the 4 Ile-de-France ewes in which the total follicular population was determined the mean mitotic index and the number of follicles were determined for 8 follicle size classes (follicle class $<0.06 \mathrm{~mm}$ diameter was not included as the number of follicles was not determined). Highly significant, linear, negative correlations for each ewe were found between the mean mitotic index $(y)$ and the number of follicles in each class $(x)$ and the slopes of these regressions differed between ewes, being $y=1.26-0.02 x, r^{2}=0.83 ; y=1.77-0.05 x$, $r^{2}=0.74 ; y=1.33-0.03 x, r^{2}=0.56$; and $y=1.14-0.02 x, r^{2}=0.96$. When the data were considered for the same class in each of the 4 different ewes, there were no significant correlations between mitotic index and number of follicles per class.

Table 2. Mean doubling times and times to pass through each follicular class in ovaries from 8 Romanov and 8 Ile-de-France ewes (pooled regardless of season of study)

\begin{tabular}{lcccccccc}
\hline & \multicolumn{7}{c}{ Follicle class by diameter (mm) } \\
\cline { 2 - 8 } & $0.06-0 \cdot 10^{*}$ & $0.11-0.20 \dagger$ & $0.21-0.35$ & $0.36-0.62$ & $0.63-1.13$ & $1.14-2.00$ & $>2.01 \ddagger$ \\
\hline Doubling time (h) & 831 & 520 & 244 & 99.0 & 66.0 & 71.0 & 86.5 \\
\hline $\begin{array}{l}\text { Time to pass } \\
\text { through class (days) }\end{array}$ & 78 & 52 & 19.3 & 8.1 & 3.8 & 6.1 & 7.3 \\
\hline
\end{tabular}

* 3 layers of granulosa cells at start of this class.

$\dagger$ Antrum formation at about this size.

$\ddagger$ Follicles become preovulatory in this class.
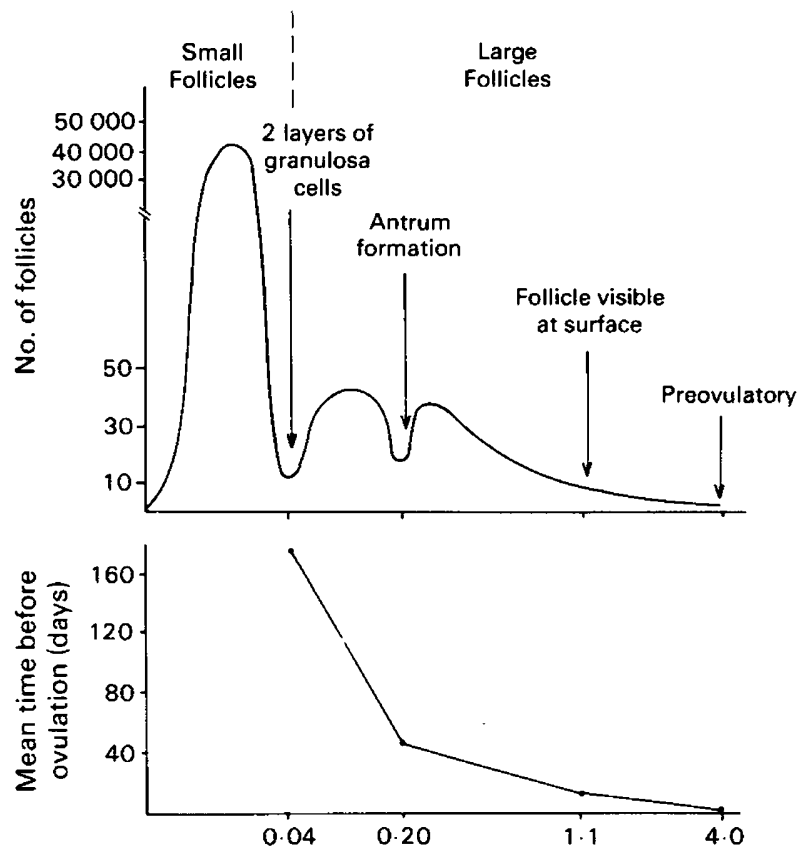

Follicle size by diameter ( $\mathrm{mm}$ )

Text-fig. 3. Schematic diagram of the follicular populations (taken from Cahill et al., 1979) and the overall mean time taken for a follicle to grow from 3 layers of granulosa cells until the preovulatory stage in 8 Romanov and 8 Ile-de-France ewes. 


\section{Calculation of the duration of mitosis and time sequences}

Since no significant differences between breed, season or cycle could be detected all results were pooled per class to calculate the mean ( \pm s.e.m.) duration of mitosis which was found to be $1.38 \pm 0.07 \mathrm{~h}$. The calculated doubling time varied greatly between follicular classes (Table 2); before the start of antrum formation the doubling times were very long and then decreased as the follicle increased in size. The overall mean time for a follicle to pass from 3 layers of granulosa cells ( 200 cells) to the start of antrum formation (5000 cells) was 130 days (4.3 months), whilst to pass from antrum formation to the preovulatory stage was 44.6 days (approx. 2.5 cycles), and the overall mean time was approximately 6 months (Text-fig. 3 ).

\section{Discussion}

Our study of the accumulation function of granulosa cells at the metaphase-anaphase stage after colchicine treatment has verified in the sheep ovary the function described by Puck \& Steffen (1963) from in-vitro studies and enabled us to extrapolate our results according to a time basis. A schematic diagram of the number of follicles (Cahill et al., 1979) and their growth rate (Text-fig. 3) shows that it takes 6 months for a follicle to grow throughout the growth phase and demonstrates the slow rate of folliculogenesis in sheep. Our results for the growth of antral follicles agree with those of Turnbull, Braden \& Mattner (1977) who reported $1062 \mathrm{~h}$ (44.3 days) for a follicle to pass from $0.19 \mathrm{~mm}$ diameter to the preovulatory stage in Merino ewes ( $1070 \mathrm{~h}$ for the same stage in Romanov and Ile-de-France ewes, in the present study), although Turnbull et al. (1977) estimated the duration of mitosis as $0.43 \mathrm{~h}$ and we obtained a value $1.38 \mathrm{~h}$ calculated from about 1000 follicles. Mazia (1961) concluded in his review that the duration of mitosis is generally between 0.5 and $3.0 \mathrm{~h}$. Dufour, Cahill \& Mauléon (1979) reported that a new wave of follicles released into the growth phase after unilateral ovariectomy of crossbred ewes grew to $0.09 \mathrm{~mm}$ in diameter after 70 days and this agrees well with the value in the present study of 78 days to grow to a diameter of $0.10 \mathrm{~mm}$, adding further support to our estimation of growth rate.

Before antrum formation the follicular growth process is very slow (130 days) but thereafter follicles soon enter the rapid growth phase (45 days). One of the problems in evaluating the mean growth rate of the very large follicles is that the one or two follicles selected to ovulate may have a distinctly different growth rate from the overall mean growth rate. Secondly, very early atresia in other follicles which is undetectable by histological means may decrease the overall mean growth rate. These two effects may account for the large variations seen in these classes.

The follicles which finally ovulate in the breeding season must have begun their growth in the anoestrous season, 6 months before. Our results, although admittedly based on a very few animals, show that there are more small preantral follicles (i.e. entering the preantral phase) and fewer antral follicles (i.e. follicles leaving the preantral phase) during the anoestrous period, which would suggest that the total number of preantral follicles is increasing in anoestrus and falling in the breeding season whilst the antral follicle population follows an inverse fluctuation. Such an hypothesis may demonstrate a role or necessity of the anoestrous period in sheep and requires further investigation.

The negative correlations per animal between the number of follicles in a class and the mitotic index of that class suggest that, within an ovary, the number of follicles in a class is limited and that the growth rate of follicles is adjusted according to this need (see Peters, 1973). Such a mechanism would ensure that the growth phase is always full of its complement of follicles at a given time; i.e. from initiation of follicle growth, each follicle grows at an accelerated rate until it arrives at a class which almost has its complement of follicles, whereupon the 
follicle's growth rate is decreased and the class is filled up. The growth rate of all follicles would thus be controlled by the largest follicles. Such a mechanism could be regulated by a negative feedback system acting through the largest follicle(s) because the largest one or two follicles are mainly responsible for oestrogen secretion and therefore for exerting the negative feedback effect (Baird \& Scaramuzzi, 1976). An intra-ovarian regulation mechanism could therefore exist which is at least partly linked to the hypothalamic-hypophysial-ovarian axis.

A large variation between animals existed in follicular growth rate as determined by mitotic indices and no differences could be detected between breed, cycle or season. Turnbull, Land \& Scaramuzzi (1978) reported a breed difference in follicular growth rates but individual animal variations were not considered in their study which may explain the difference in conclusions. Using the individual animal variations we have observed in follicular growth rates, it can be calculated that 300 ovaries must be examined microscopically to show a significant breed difference. A similar large individual variation has also been reported for the number of large follicles per ovary (Cahill et al., 1979).

Follicular characteristics were very stable and unaffected by cycle, breed or season. The increase in oocyte diameter and antrum with follicle size has been well demonstrated in most species (Brambell, 1956). In sheep, irrespective of season, cycle or breed, 3 important events occur at a particular follicle size: (1) the oocyte enters a very slow growth phase after reaching almost maximum size, (2) antrum formation begins, and (3) the rapid growth phase of the follicles starts. Before this size there is a large number of follicles which have practically no atresia (Cahill et al., 1979) and a very slow growth rate, suggesting that this group of follicles may act as a short-term buffer between the dormant primordial and actively growing antral follicles.

We thank Mrs Francois Berthelot and Mr C. Cornu for their enthusiasm and technical assistance throughout the experiment. One of us (L.P.C.) was on study leave from the Animal Research Institute, Werribee, Australia, and was supported by the Australian Wool Corporation Trust Fund during this project.

\section{References}

Abercrombie, M. (1946) Estimation of nuclear population from microtome sections. Anat. Rec. 94, $239-247$.

Baird, D.T. \& Scaramuzzi, R. (1976) The source of ovarian oestradiol and androstenedione in the sheep during the luteal phase. Acta endocr., Copenh. 83, $402-409$.

Brambell, F.W.R. (1956) Ovarian changes. In Marshall's Physiology of Reproduction, 3rd edn, Vol. 1, pp. 397-542. Ed. A. S. Parkes. Longmans Green, London.

Cahill, L.P., Mariana, J.C. \& Mauléon, P. (1979) The total follicular populations in ewes of high and low ovulation rates. J. Reprod. Fert. 55, 27-36.

Dufour, J., Cahill, L.P. \& Mauléon, P. (1979) Short- and long-term effects of hypophysectomy and lateral ovariectomy on follicular populations in sheep. J. Reprod. Fert. 57, 301-309.
Mazia, D. (1961) Mitosis and the physiology of cell division. In The Cell, Biochemistry, Physiology and Morphology, Vol. III, pp. 77-412. Eds J. Brachet \& A. E. Mirsky. Academic Press, New York.

Puck, T.T. \& Steffen, J. (1963) Life cycle analysis of mammalian cells. 1. A method for localizing metabolic events within the life cycle, and its application to the action of colcemide and sublethal doses of X-irradiation. Biophys. J. 3, 379-397.

Peters, H. (1973) Development and atresia of follicles in the immature mouse. Annls Biol. anim. Biochim. Biophys. 13, 167-174.

Turnbull, K.E., Braden, A.W.H. \& Mattner, P.E. (1977) The pattern of follicular growth and atresia in the ovine ovary. Aust. J. biol. Sci. 30, 229-241.

Turnbull, K.E., Land, R.B. \& Scaramuzzi, R.J. (1978) Patterns of growth of graafian follicles in sheep and their relationship to ovulation rate. Theriogenology 8, 172, Abstr. 